\title{
Short stature in Noonan syndrome: response to growth hormone therapy
}

Department of

Endocrinology,

Birmingham

Children's Hospital,

Birmingham, UK

J M W Kirk

Department of

Paediatrics,

Southampton General

Hospital,

Southampton, UK

P R Betts

Department of

Paediatric

Endocrinology, Leeds

General Infirmary,

Leeds, UK

G E Butler

Royal Hospital for Sick Children, Yorkhill, Glasgow, UK

M D C Donaldson

Department of Paediatrics, John Radcliffe Hospital,

Headington, UK

D B Dunger

Children's

Department, Queen's

Medical Centre,

Nottingham, UK

D I Johnston

Royal Hospital for Sick Children, Edinburgh,

UK

C J H Kelnar

Royal Manchester Children's Hospital, Pendlebury,

Manchester, UK

D A Price

Pharmacia \& Upjohn, Stockholm, Sweden

P Wilton

Correspondence to:

Dr Kirk

Jeremy.Kirk@BhamChildrens. WMids.NHS.UK

Accepted 3 April 2000

J M W Kirk, P R Betts, G E Butler, M D C Donaldson, D B Dunger, D I Johnston, C J H Kelnar, D A Price, P Wilton, the UK KIGS Executive Group on behalf of the participating centres

\begin{abstract}
Background-Growth hormone (GH) has been used to promote growth in both the short and long term in a number of dysmorphic syndromes, including Turner syndrome. As this condition shares many clinical features with Noonan syndrome, it would seem logical to treat the latter group with GH.

Aims-To assess the short and long term response to GH therapy in patients with Noonan syndrome.

Methods-Analysis of patients with Noonan syndrome in the Pharmacia \& Upjohn International Growth Study (this postmarketing database contains data on the majority of patients currently treated with GH in the UK). A questionnaire was also sent to participating clinicians.

Results-Data on 66 patients (54 males) were available for study. At the start of GH therapy children were short, compared with both normal and Noonan children. During the first year of GH therapy height velocity increased from a mean of 4.9 to $7.2 \mathrm{~cm}$ per year. For patients treated long term with GH, mean height SDS increased from -2.9 pretreatment to -2.6 after one year and $\mathbf{- 2 . 3}$ after five years. Of the 10 patients at near final height, only one had a height above the 3rd centile for normal adults and above the mean for untreated Noonan patients. The mean increment in final height was $3.1 \mathrm{~cm}$ (range -1.1 to $6.5 \mathrm{~cm}$ ).

Conclusions-GH therapy in patients with Noonan syndrome will improve height velocity in the short term. Longer-term therapy results in a waning of effect; initial indications are that final height is not improved substantially in most patients. (Arch Dis Child 2001;84:440-443)
\end{abstract}

Keywords: Noonan syndrome; short stature; growth hormone

Noonan syndrome, a constellation of dysmorphic features initially described in $1963,{ }^{1}$ occurs with a prevalence of approximately 1 in 1000. Dominant inheritance with incomplete penetrance is often found in affected families, and the gene for Noonan syndrome has now been mapped to chromosome $12 \mathrm{p}$. At present, the diagnosis is a clinical one and a number of scoring systems exist. ${ }^{2}{ }^{3}$ Short stature is common, with $83 \%$ of affected children in one series having a height below the $3 \mathrm{rd}$ centile. ${ }^{4}$
Another study of 144 patients showed that birth weight is usually normal, with poor prepubertal growth and delayed puberty. Final height is often compromised, with mean adult height for males $162.5 \mathrm{~cm}$, and for females $152.7 \mathrm{~cm} .^{5}$

The cause of the short stature in Noonan syndrome is unclear. Although insulin like growth factor 1 (IGF-1) concentrations are reported as low or low normal, formal anterior pituitary function testing is usually normal, ${ }^{6}$ as is spontaneous growth hormone secretion. ${ }^{7}$ Other endocrine abnormalities described include hypogonadism and autoimmune thyroiditis.

Noonan syndrome shares many phenotypic features with Turner syndrome; it was previously referred to as "male Turner's", although males and females are affected with an equal sex incidence. Because of the clinical similarities between Noonan and Turner syndrome, and because growth hormone can improve short term growth and final height in patients with Turner syndrome, it would appear logical to treat patients with Noonan syndrome.

This report analyses those patients with Noonan syndrome from the UK who have been treated with growth hormone and whose growth data have been analysed in the Pharmacia \& Upjohn International Growth Study (KIGS). This is an international post-marketing surveillance database of children with various growth disorders treated with growth hormone $(\mathrm{GH})$. The database was established in 1987, and now includes data on over 30000 patients in 43 countries. Within the UK, data on 4400 patients (2350 ongoing) from 40 centres are now loaded onto the database, and represent over two thirds of the total UK paediatric population currently treated with $\mathrm{GH}$.

Patients and methods

All patients with a clinical diagnosis of Noonan syndrome (Code 3.3.2) on the UK KIGS database were included. In addition to the biochemical and auxological data on the database, all Noonan patients have a further disease specific sheet which provides further clinical details. We also requested further data by questionnaire from clinicians as to whether the patient had received oxandrolone, testosterone, or oestrogen in addition to $\mathrm{GH}$; how often echocardiography had been performed during $\mathrm{GH}$ therapy; and if applicable, the reasons for stopping $\mathrm{GH}$ and the outcome thereafter.

Reference data were drawn from the standards of Tanner and Whitehouse ${ }^{8}$ for normal children, and Ranke and colleagues ${ }^{5}$ for 
Table 1 Details of patients at start of $G H$ therapy $(n=66)$

\begin{tabular}{lllr}
\hline Baseline & $N$ & Mean & SD \\
\hline Birthweight SDS & 53 & -0.5 & 1.3 \\
Maximal GH peak (ng/ml) & 55 & 16.8 & 10.2 \\
Target height SDS & 64 & -0.4 & 0.9 \\
Chronological age (year) & 66 & 10.2 & 3.3 \\
Bone age ("year") & 27 & 8.1 & 2.9 \\
Height SDS & 66 & -2.9 & 0.7 \\
Height velocity (cm/y) & 35 & 4.8 & 1.1 \\
Dose of GH (U/kg/week) & 66 & 0.79 & 0.24 \\
\hline
\end{tabular}

Noonan children. Bone ages were calculated using the method of Tanner and colleagues. ${ }^{9}$ The results are shown as mean (SD) where appropriate. Statistical analysis was by SAS, version 6,12/AIX.

\section{Results}

A total of 66 patients with Noonan syndrome (54 males, $82 \%$ ) have been included. Subjective overall assessment of the features of Noonan syndrome by the referring clinician was minor in $22 \%$, moderate in $65 \%$, and severe in $13 \%$. Seventy eight per cent of patients had a cardiac malformation, and $48 \%$ had had corrective cardiac surgery. Of the males, $67 \%$ gave a history of cryptorchidism. Twenty five per cent had a family history of Noonan syndrome.

\section{PRETREATMENT DATA}

Table 1 and fig 1 show pretreatment and first year therapy data. As there was no significant difference between the two sexes, data were pooled. Information on birth weight was available in 53 children; mean birth weight standard deviation score (BwSDS) was -0.5 for all patients. Fifty five patients had anterior pituitary function assessed, with a mean (SD) GH peak of $16.8(10.2) \mathrm{ng} / \mathrm{ml}$ (normal >10).

At commencement of $\mathrm{GH}$, children were short compared to both the normal and Noonan population (mean (SD) height SDS: $-2.9(0.7)$ and $-1.2(0.8)$ respectively). At start of therapy, mean (SD) age was 10.2 (3.3) years, and bone age (only available in 27 children) was delayed by a mean of 2.7 "years". Seven were already in established puberty. Six patients were additionally receiving thyroxine.

FIRST YEAR OF GH THERAPY

The mean (SD) dose of $\mathrm{GH}$ was $0.79(0.24)$ $\mathrm{U} / \mathrm{kg} /$ week, with the majority of patients receiving seven injections per week. During the first year of GH therapy, height velocity $(\mathrm{n}=35)$ increased from a pretreatment mean (SD) of $4.8(1.1)$ to $7.2(1.7) \mathrm{cm} / \mathrm{y}(\mathrm{p}<0.05$; fig 1$)$. When expressed as height velocity SDS scores, the mean (SD) rose from $-0.9(1.8)$ to $1.9(2.5)(p<0.05)$. During the same period the mean height SDS rose by 0.3 and 0.4 for normal and Noonan populations respectively (both $\mathrm{p}<0.05$ ). Bone age increased by a mean (SD) of 1.0 (0.7) "years" during the year of therapy.

LONG TERM THERAPY

Patients have continued on GH therapy for up to six years (fig 2), although the numbers have steadily declined to only 13 patients treated at

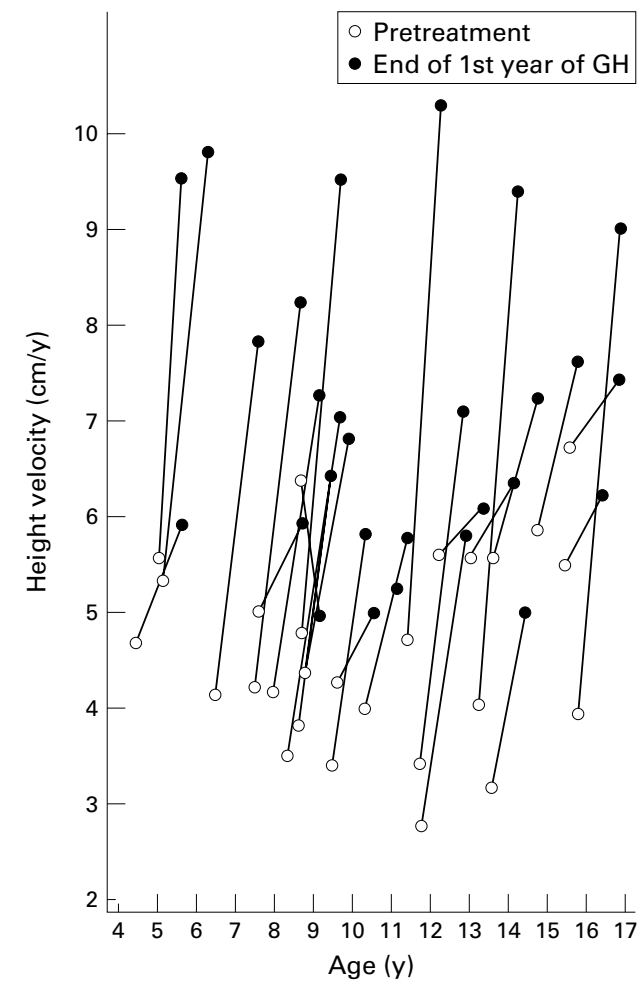

Figure 1 Height velocity during first year of $G H$ treatment $(n=27)$.

the end of this period. Height SDS increased from a mean (SD) of $-2.9(0.7)$ at the start of GH therapy to $-2.6(0.8)$ after one year of therapy, and $-2.3(0.7)(\mathrm{n}=13)$ after six years. When plotted using Noonan data the mean (SD) height SDS increased from -1.1 (0.8) to $-0.7(0.9)$ after one year of $\mathrm{GH}$ therapy to -0.3 (0.9) after six years. Although the increase between height SDS for both normal and Noonan data was significantly greater after three years of $\mathrm{GH}$ therapy compared to one, the sixth year data was not. The dose of $\mathrm{GH}$ fell progressively to a mean of $0.63 \mathrm{U} / \mathrm{kg} /$ week after six years, although the number of injections remained at seven per week in the majority of patients throughout the course of treatment. Eleven patients have received additional therapy with either oxandrolone, testosterone, or oestrogen.

Reasons for stopping $\mathrm{GH}$ included cardiac decompensation $(n=1)$ and worsening of kyphoscoliosis $(n=1)$; one patient had their GH stopped for a month when they developed headache and vomiting (but no papilloedema). Other reasons were poor growth $(n=6)$, noncompliance $(\mathrm{n}=4)$, and the patient's decision to stop therapy $(n=3)$. Echocardiograms were performed yearly in $40 \%$, and two yearly in $20 \%$; in $14 \%$ of patients, none were performed while on therapy.

\section{FINAL HEIGHT}

Data are available on 10 patients with Noonan syndrome treated to near final height (defined as $>15$ years in girls and $>17$ years in boys, and with a height velocity $<2.5 \mathrm{~cm} / \mathrm{y}$; table 2 ). Mean final height was $147.2 \mathrm{~cm}$ (range 142.9151.4) in girls and $159.9 \mathrm{~cm}$ (range 155.6- 


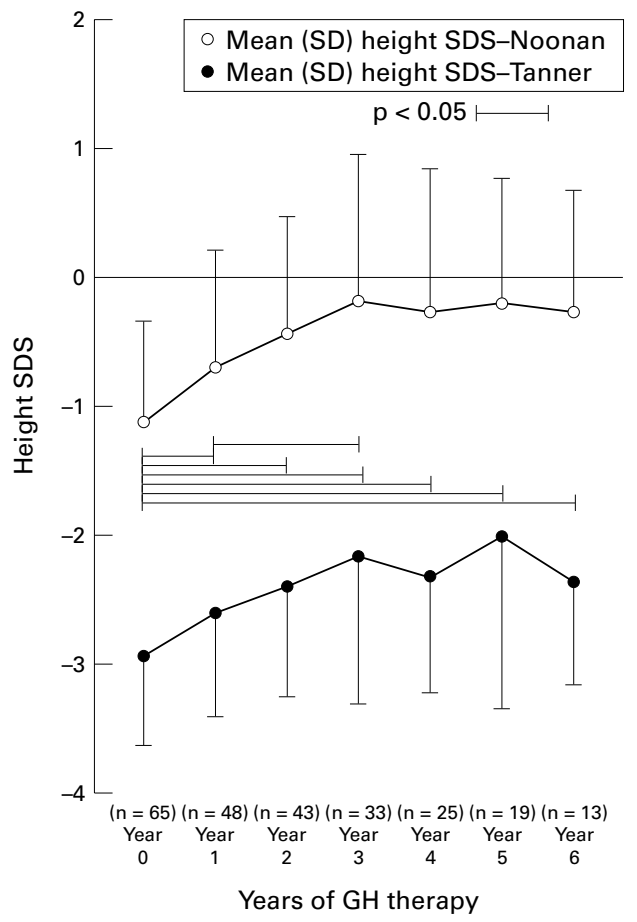

Figure 2 Mean (SD) height SDS for Noonan and Tanner standards during GH therapy.

166.2) in boys. Two boys received oxandrolone or testosterone in addition to $\mathrm{GH}$. The change in height SDS for chronological age on therapy for both sexes was +0.8 SDS using TannerWhitehouse standards; and +1.2 for Noonan reference standards if plotted for chronological age, and +0.6 if plotted against final height centiles. If, as with Turner syndrome, ${ }^{10}$ the predicted adult height was extrapolated from the pretreatment height centile on the Noonan chart, final height was increased by a mean of $3.1 \mathrm{~cm}$ (range -1.1 to $6.5 \mathrm{~cm}$ ), with two patients (both male) increasing their predicted final height by $5 \mathrm{~cm}$ or more.

\section{Discussion}

This analysis has reviewed the use of $\mathrm{GH}$ in patients with Noonan syndrome in the UK. In our study the patients were of relatively low birth weight, and also short compared not only to normal, but also Noonan standards. This phenomenon has also been noted in other patients on the KIGS international database, ${ }^{11}{ }^{12}$ and presumably reflects the selection criteria used in these patients.

The patients in this study were growing slowly pretreatment, and had a significant increase in height velocity during the first year of GH therapy. After three years of continuous treatment there was no further increase in height SDS, either compared with normal or Noonan children. This is despite the fact that those children who were growing poorly were either stopped or made the decision themselves to stop GH therapy. In addition, final height data in these patients was relatively disappointing, with a mean increase in final height of only $3.1 \mathrm{~cm}$, and only the minority having an increase of $>5 \mathrm{~cm}$. Although there may be some underestimation of final height (as a number of patients were still growing at the end of the study), it is unlikely that this difference would be substantial as the mean height velocity was only $0.8 \mathrm{~cm} / \mathrm{y}$ in this group. In addition, although three patients did have final heights within their genetically predicted range (target height $\pm 10 \mathrm{~cm}$ ), even this may be unhelpful as a number had parents affected with Noonan syndrome (as would be expected from an autosomally dominant inherited disorder).

Untreated Noonan patients continue to grow into their late teens (a mean of $2.0 \mathrm{~cm}$ for girls, and $8.6 \mathrm{~cm}$ for boys from the age of 17 years $)^{5}$; assessment of changes in height SDS for chronological age using Noonan standards in patients treated with $\mathrm{GH}$ are therefore likely to overestimate height gains. As not all patients had had pretreatment bone ages performed, and as extrapolation of the pretreatment height centile to adult height on disease specific charts has been found to be superior to both TannerWhitehouse ${ }^{10}{ }^{13}$ and Bayley-Pinneau ${ }^{13}$ methods of height prediction in Turner syndrome, we have chosen the former method to predict untreated final height.

The growth response of patients with Noonan syndrome to GH has previously been assessed in a number of studies. Cotterill and colleagues $^{14}$ showed a significant increase in height velocity of more than $2 \mathrm{~cm} / \mathrm{y}$ in 24/30 patients over one year. Both Tanaka ${ }^{15}$ and De Schepper and colleagues ${ }^{16}$ noted that the

Table 2 Details of patients treated to final height

\begin{tabular}{|c|c|c|c|c|c|c|c|c|c|c|c|}
\hline \multirow[b]{2}{*}{ Sex } & \multirow[b]{2}{*}{ Age } & \multirow[b]{2}{*}{ Years of $G H$} & \multirow{2}{*}{$\begin{array}{l}\text { Target height } \\
\text { (cm) }\end{array}$} & \multirow{2}{*}{$\begin{array}{l}\text { Final height } \\
(\mathrm{cm})\end{array}$} & \multicolumn{3}{|c|}{ Height SDS } & \multicolumn{4}{|c|}{ Height SDS (Noonan) } \\
\hline & & & & & Start & End/CA & $\triangle / C A$ & Start & $E n d / F H$ & $\Delta / F H$ & $\Delta / F H(\mathrm{~cm})$ \\
\hline $\mathrm{F}$ & 15.9 & 6.5 & 151.4 & 151.4 & -2.8 & -1.8 & 1.0 & -0.9 & -0.2 & 0.7 & 4.0 \\
\hline $\mathrm{F}$ & 15.7 & 8.2 & 158.6 & 142.9 & -3.6 & -3.2 & 0.4 & -1.9 & -1.6 & 0.3 & 1.7 \\
\hline $\mathrm{F}$ & 17.9 & 4.9 & 158.3 & 146.9 & -4.0 & -2.6 & 1.4 & -1.6 & -0.9 & 0.7 & 4.0 \\
\hline $\mathrm{F}$ & 16.7 & 1.8 & 164.5 & 147.6 & -3.5 & -2.4 & 1.1 & -1.0 & -0.8 & 0.2 & 1.1 \\
\hline Mean & & 5.4 & 158.2 & 147.2 & -3.5 & -2.5 & 1.0 & -1.4 & -0.9 & 0.5 & 2.7 \\
\hline$M$ & 17.6 & 4.6 & 175.8 & 166.2 & -2.3 & -1.2 & 1.1 & -0.6 & +0.6 & 1.2 & 6.5 \\
\hline M & 19.4 & 5.6 & 170.5 & 155.6 & -3.9 & -2.9 & 1.0 & -2.5 & -1.4 & 1.1 & 5.9 \\
\hline M & 17.0 & 7.2 & 179.2 & 162.3 & -2.5 & -1.8 & 0.7 & -0.7 & -0.2 & 0.5 & 2.7 \\
\hline M & 18.8 & 5.3 & 164.4 & 159.0 & -3.1 & -2.4 & 0.7 & -1.7 & -0.8 & 0.9 & 4.9 \\
\hline M & 17.5 & 5.0 & 174.8 & 159.8 & -2.1 & -2.2 & -0.1 & -0.4 & -0.6 & -0.2 & -1.1 \\
\hline M & 17.3 & 3.7 & 177.5 & 156.5 & -3.1 & -2.7 & 0.4 & -1.4 & -1.2 & 0.2 & 1.1 \\
\hline Mean & & 5.3 & 173.7 & 159.9 & -2.8 & -2.2 & 0.6 & -1.2 & -0.6 & 0.6 & 3.3 \\
\hline Mean (all) & & 5.3 & & & -3.1 & -2.3 & 0.8 & -0.7 & 0.6 & 0.6 & 3.1 \\
\hline
\end{tabular}

$\Delta / \mathrm{CA}$ : change in height centile based on chronological age.

$\Delta / \mathrm{FH}$ : change in height centile based on final height. 
responses to $\mathrm{GH}$ in patients with Noonan syndrome were similar to those with Turner syndrome. In the International KIGS study, ${ }^{11}$ which looked at 55 patients, a lower dose of $\mathrm{GH}$ was used (median $0.61 \mathrm{U} / \mathrm{kg} /$ week) and produced an increase in height velocity from a median of $4.3 \mathrm{~cm} / \mathrm{y}$ pretreatment to $7.0 \mathrm{~cm} / \mathrm{y}$ after one year. Height SDS showed a median increase of 0.5 for normal and 0.2 for Noonan standards during the first year of therapy, but with a subsequent waning of effect over the subsequent years, with only small numbers of patients treated $(n=11)$.

Information on long term therapy is often limited to small numbers of patients in other studies. The National Cooperative Growth Study ${ }^{17}$ evaluated the response to $\mathrm{GH}$ in 150 patients with Noonan syndrome. These children were significantly shorter than those with idiopathic GH deficiency (IGHD) and Turner syndrome, with growth rates for years 1, 2, 3, and 4 intermediate for that between IGHD and Turner syndrome. There was a significant improvement in height SD scores in those 42 children who were monitored for at least four years of GH therapy. Three out of six boys who achieved adult height exceeded pretreatment predicted heights. In the International KIGS study $^{12}$ containing 143 patients, there was an increase in height SDS (Noonan standards) of 0.5 SDS for boys and 1.1 SDS for girls after three years of GH therapy. A subgroup treated to near final height showed a mean increase in height SDS of 1.5 for Tanner and 2.4 for Noonan standards. In another study, final height in a small number of patients treated for at least three years with $\mathrm{GH}$ showed that three of four had exceeded their predicted final height, and two of four exceeded their corrected midparental height. ${ }^{18}$

In conclusion, therapy with $\mathrm{GH}$ for up to six years in a group of short patients with Noonan syndrome has been shown to increase height velocity and height SDS compared to both normal and Noonan children, although there is a waning of effect after three years. Preliminary data suggest that while final height is increased in this group, the minority of patients improved their height prediction by more than $5 \mathrm{~cm}$. This is very similar to the response to $\mathrm{GH}$ seen in patients with Turner syndrome. ${ }^{19}$ Although patients in the current, predominantly retrospective study were relatively old at commencement of GH therapy and some received relatively low doses of $\mathrm{GH}$, which could account for the poor overall response, they were not dissimilar in both age and GH dose regime from other studies in Noonan ${ }^{12}{ }^{17}$ and Turner syndrome. ${ }^{19}$ Further prospective studies are required to see whether $\mathrm{GH}$ is of benefit long term in this group of patients.

We would like to acknowledge the assistance of all contributing centres to the KIGS database, which is sponsored by Pharmacia \& Upjohn.

1 Noonan JA, Ehmke DA. Associated non-cardiac malformations in children with congenital heart disease. 7 Pediatr 963:63:468-70

2 Duncan WJ, Fowler RS, Farkes LG. A comprehensive scoring system for evaluating Noonan syndrome. Am $\mathcal{F} \mathrm{Med}$ Genet 1981;10:37-50.

3 Sharland M, Burch M, McKenna Wm, Paton MA. A clinical study of Noonan syndrome. Arch Dis Child 1992;67: $178-83$.

4 Nora JJ, Nora AH, Sinha AK, Spangler RD, Lubs HA. The Ullrich-Noonan syndrome (Turner phenotype). Am f Dis Child 1974;127:48-55.

5 Ranke MB, Heidemann P, Knupfer C, et al. Noonan syndrome. Growth and clinical manifestations in 144 cases. Eur 7 Pediatr 1988;148:220-7.

6 Ahmed ML, Foot ABM, Edge JA, et al. Noonan's syndrome: abnormalities of the growth hormone/IGF-1 axis and the response to treatment with human biosynthetic human response to treatment with human biosynthetic human hormone. Acta Paediatr Scand 1991;80:446-50.

7 Spadoni GL, Bernardini S, Cianfarani S. Spontaneous growth hormone secretion in Noonan's syndrome. Acta Paediatr Scand Suppl 1990;367:157.

8 Tanner JM, Whitehouse R, Takaishi M. Standards from birth to maturity for height, weight, height velocity and weight velocity: British children, 1965. Arch Dis Child 1966;41:613-35

9 Tanner JM, Whitehouse R, Marshall W, et al. Assessment of skeletal maturation and prediction of adult height (TW2 method). London: Academic Press.

10 Lyon AJ, Preece MA, Grant DB. Growth curve for girls with Turner syndrome. Arch Dis Child 1985;60:932-5.

11 Otten B. Short stature in Noonan syndrome: demography and response to growth hormone treatment in the Kabi International Growth Study. In: Ranke MB, Gunnarsson $\mathrm{R}$, eds. Progress in growth hormone therapy-5 years of KIGS. Mannheim: J \& J Verlag, 1994.

12 Otten BJ, Noordam K. Short stature in Noonan syndrome: demography and response to growth hormone treatment in KIGS. In: Ranke MB, Gunnarsson R, eds. Growth hormone therapy in KIGS: 10 years experience. Mannheim: J \& J Verlag, 1999 .

13 Naeraa RW, Eiken M, Legarth EG, Nielsen J. Spontaneous growth, final height and prediction of final height in Turner syndrome. In: Ranke MB, Rosenfeld RG, eds. Turner syndrome: growth promoting therapies. Amsterdam: Elsevier Science, 1991:113-16.

14 Cotterill AM, McKenna WJ, Brady AF, et al. The short-term effects of growth hormone therapy on height velocity and cardiac ventricular wall thickness in children with Noonan's syndrome. F Clin Endocrinol Metab 1996;81: 2291-7

15 Tanaka T. Growth hormone treatment in Noonan syndrome. Acta Paediatr Fpn 1996;38:99-101.

16 De Schepper J, Otten BJ, Francois I, et al. Growth hormone therapy in pre-pubertal children with Noonan syndrome: first year growth response and comparison with Turner syndrome. Acta Paediatr 1996;86:943-6.

17 Romano AA, Blethen SL, Dana K, Noto RA. Growth hormone treatment in Noonan syndrome: the National hormone treatment in Noonan syndrome: the National S18-21.

18 Municchi G, Pasquino AM, Pucarelli I, et al. Growth hormone treatment in Noonan syndrome: report of four cases who reached final height. Horm Res 1995;44:164-7.

19 Betts PR, Butler GE, Donaldson MDC, et al. A decade of growth hormone treatment in girls with Turner syndrome in the UK. Arch Dis Child 1999;80:221-5. 